\title{
A plant economics spectrum in Mediterranean forests along environmental gradients: is there coordination among
}

\section{leaf, stem and root traits?}

Enrique G. de la Riva ${ }^{*}$, Ambra Tosto ${ }^{1}$, Ignacio M. Pérez-Ramos ${ }^{2}$, Carmen M. Navarro-Fernández ${ }^{2}$, Manuel Olmo ${ }^{1}$, Niels P.R. Anten ${ }^{3}$, Teodoro Marañón ${ }^{2}$ and Rafael Villar ${ }^{1}$

${ }^{1}$ Área de Ecología, Facultad de Ciencias, Universidad de Córdoba, 14071 Córdoba, Spain; ${ }^{2}$ Instituto de Recursos Naturales y Agrobiología de Sevilla, IRNAS, CSIC, 41012 Seville, Spain; ${ }^{3}$ Centre for Crop Systems Analysis, P.O. Box 4706700 AK, Wageningen,Wageningen University, The Netherlands

* Corresponding author: enga70@gmail.com

Short title: Plant economics spectrum in Mediterranean forests 


\section{Abstract}

Questions: Is there any evidence of coordination among leaf, stem and root traits and, thereby, of the existence of a plant economics spectrum at the species and community level in Mediterranean forests? Are these traits related to plant size and seed mass?

Location: Mediterranean forests and shrublands of the Sierra Morena mountains (Córdoba, southern Spain).

Methods: We selected nine woody plant communities along a natural local gradient of soil water and nutrient availability. We measured key leaf, stem, root and whole-plant traits for 38 dominant woody plant species. The variation across species of 15 functional traits (of the leaf, stem and root) was analysed and the coordination among them was tested. We explored the relationships between these traits (hereafter named "resource-use traits" due to their close association with the acquisition-conservation trade-off) and plant height and seed mass. Finally, we compared the results at the species level with those calculated at the community level, considering community-weighted means (CWMs).

Results: We found a significant coordination between traits belonging to different plant organs, and propose the existence of a plant economics spectrum in Mediterranean forests along the environmental gradient. However, weaker relationships were found within groups of species under similar environmental conditions. We did not find the expected orthogonal relationships between plant height, seed mass and resource-use traits. Relationships among functional traits were stronger at the community level than at the species level.

Conclusions: This study reveals a high degree of functional coordination between traits belonging to different plant organs at both the species and community level, and suggests the existence of a plant economics spectrum across 38 Mediterranean woody plant species. However, this 
general trend of functional coordination between organs became weaker or disappeared when considering restricted groups of species belonging to environmentally similar sites (e.g. dry versus wet sites), suggesting that the diversification of strategies within communities is not related to the economics spectrum at a lower spatial scale. Interestingly, the high degree of coordination between resource-use traits and seed mass at the community level seems to support the tolerance-fecundity model, which predicts an inverse relationship between fecundity and stress tolerance.

Keywords: Acquisition-conservation trade-off; Functional trait; LHS scheme; Phylogenetically independent contrasts; Root dry matter content, Seed mass; Specific leaf area; Tolerance-fecundity model.

\section{Nomenclature}

Castroviejo, S. (1986-2012) 


\section{Introduction}

Functional plant traits are commonly-used indicators of species ecological functions, as they allow us to better understand plant strategies and distribution (Violle et al. 2007; Reich 2014). Thus, the functional trait approach has been used as a tool to comprehend the spectrum of functional strategies in plants and their relationships with the environment (Garnier \& Navas 2012 and references therein). The trade-off between acquisition and conservation of resources is a good example of different functional strategies in plants, which can be described by the range of trait variation that defines the broadly-known leaf economics spectrum (Díaz et al. 2004; Wright et al. 2004). This spectrum runs from species with a conservative resource-use strategy (i.e. sclerophyllous, long-lived leaves and low photosynthetic rates), to those with contrasting traits commonly associated with rapid resource capture and a high relative growth rate (Reich et al. 1998a; Wright \& Westoby 2001; Villar et al. 2006; Poorter \& Garnier 2007). However, the extent to which this paradigm can be extended to other organs, like roots and stems, and to the level of the whole plant still remains unclear (Freschet et al. 2010; Prieto et al. 2015). Thus, there is controversy about how the traits of different plant organs (i.e. leaf, stem and root) co-vary across species and the extent to which this co-variation adheres to a plant economics spectrum (Freschet et al. 2010; Laughlin et al. 2010).

Some recent studies have reported that the trade-off between acquisition and conservation of resources can be also extrapolated to the below-ground component (Birouste et al. 2012; Prieto et al. 2015), providing support for the hypothesis that the paradigm of the leaf economics spectrum can be extended to the whole-plant level (Freschet et al. 2010). Recently, Pérez-Ramos et al. (2012) found evidence in Mediterranean 
grasslands that plant economics could be scaled up at the community level, with potential repercussions for relevant ecosystem processes and services (e.g. Freschet et al. 2013). In these studies, leaf traits indicative of an acquisitive strategy were associated with similar acquisitive root traits, indicating that different organs converge in position along the economics spectrum. However, studies on woody plants from tropical forests did not find positive correlations between leaf and root traits (Fortunel et al. 2012) or between leaf and stem traits (Baraloto et al. 2010). These authors suggested that functional trade-offs in different tissues operate independently between components, as a result of the optimisation of the survival and growth strategies in more-highly-competitive environments, like tropical forests. The relationships between traits belonging to different organs may also change if they are affected by different environmental conditions (Cordlandwehr et al. 2013) or because different floras are subject to different evolutionary constraints (Heberling \& Fridley 2012). Therefore, we need more studies that test the coordination among leaf, stem and root traits in different environments and at different spatial scales to reach generalisations on the existence and nature of a plant economics spectrum at both the species and community level.

The leading dimensions of ecological variation among plants include not only functional traits associated with the use of resources (resource-use traits) but also those associated with competition for light (e.g. plant height) and reproductive ability (e.g. seed number and size) (Westoby \& Wright 2006; Reich 2014). Among different models, the tolerance-fecundity model (Muller-Landau 2010) assumes an inverse relationship between fecundity and stress tolerance across species. The 'Leaf-Height-Seed' scheme (LHS) proposed by Westoby (1998), and expanded to the root dimension by Laughlin et al. (2010), assumes that leaf economics is essentially independent of the dimensions of plant 
height and seed production (Liancourt et al. 2009; Laughlin 2014). However, more studies are necessary to discern whether these two models (tolerance-fecundity and LHS) can be generalised to other biomes and ecosystem types.

In this study, we explored the spectrum of variation in functional traits and the degree of coordination between leaf, stem and root traits, for the first time in Mediterranean woody plant species growing on natural conditions. The principal aim was to test the existence of a wholeplant economics spectrum in forests and shrublands of southern Spain. We also explored two additional functional dimensions: plant height and reproductive ability (particularly seed mass). The observed relationships among functional traits across plant species were then tested at the community level, using community-weighted means (CWMs; sensu Garnier et al. 2004), to prove their consistency at both organizational levels. The results obtained must be considered in a determined environmental and evolutionary context. In this case study, the environmental and evolutionary context is a species pool of 38 woody plant species sampled in nine different plant communities (including forests and shrublands) that were distributed along a local environmental gradient. We selected a wide gradient of soil water availability with the aim of spanning a large range of potentially-different resource-use strategies.

We expect to find that:

(i) The functional traits of a set of co-occurring plant species covary according to a main specialisation axis that reflects a wide range of resource-use strategies (Díaz et al. 2004; Wright et al. 2004). Under Mediterranean conditions, where plants survival and growth are commonly 
limited by the scarcity of soil water and nutrients, we expect to find a strong, positive coordination between leaf, stem and root traits, reflecting a whole-plant economics spectrum across the resource-use gradient (Freschet et al. 2010; Pérez-Ramos et al. 2012).

(ii) This general coordination of functional traits among organs may change with the spatial scale (Funk \& Cornwell 2013), for instance when considering separately sets of species inhabiting sites at different positions of the environmental gradient. Thus, we expect to find a weaker coordination of functional traits among organs when considering a restricted range of the environmental gradient (e.g. dry versus wet sites) than when analysing at a higher spatial scale (i.e. considering the whole gradient heterogeneity).

(iii) The three main functional dimensions, resource-use traits (associated with the acquisition-conservation trade-off), plant height (related to competition for light) and seed mass (related to germination, establishment and dispersal), are orthogonal, according to the 'LeafHeight-Seed' hypothesis (Westoby 1998; Laughlin et al. 2010).

(iv) Based on previous findings indicating that dominant species tend to have trait values that are better linked to their environments than those of rare species (Ackerly et al. 2002; Cingolani et al. 2007; Domínguez et al. 2012), the relationships among functional traits are stronger at the community level (using community-weighted means) than at the species level.

We tested these expectations for a set of Mediterranean forest and shrubland communities along an environmental gradient in southern Spain. 


\section{Material and methods}

\section{Study area}

The study was conducted in Mediterranean forests and shrublands located in the Sierra Morena mountains, in the south of Spain (Córdoba). The area is characterised by a continental-Mediterranean climate with cold, wet winters and dry, warm summers. The mean annual temperature is $17.6^{\circ} \mathrm{C}$ and the mean annual precipitation is $536 \mathrm{~mm}$; data from the Spanish Meteorological Agency, AEMET (1971-2000). Several shrub and arborescent species, such as Cistus albidus and Quercus coccifera are abundant in driersoils, while broadleaf deciduous trees such as Alnus glutinosa or Fraxinus angustifolia are dominant in moister soils (see Appendix S1 for details of the 38 studied species).

\section{Sampling design}

Nine sampling sites were selected along a natural and wide gradient of soil resource availability (mainly soil water, de la Riva et al. 2015). In spring 2012, four 20-m-long transects were set up randomly in each of the nine sampling sites, with a minimum distance of $10 \mathrm{~m}$ relative to one another. The species abundance and composition were measured as well as the cover of each woody species intercepted by each of the four 20-m transects. The mean relative abundance for each species and site was calculated as the mean value of the four transects. For trait measurements (see details below), we ranked the species by their relative abundance and selected those representing at least $90 \%$ of the total plant woody cover measured in each site. These species comprise most of the biomass in that community and are expected to have a major role in the functioning of 
the ecosystem (Lavorel et al. 2008). This gave a total of 38 selected species, many of them appearing in more than one sampling site (Appendix S1).

\section{Plant measurements}

In late spring 2012, during the peak of plant growth, healthy adults of the most-dominant woody plant species were selected randomly. We measured 15 key functional traits related to morphology (in the leaf, stem and root), physiology, plant size and reproduction (see functional roles in Appendix S2), covering the main functional dimensions. All these trait measurements were carried out according to the criteria defined by Pérez-Harguindeguy et al. (2013).

Leaf morphological traits.- Six individuals per species and sampling site were chosen, on which the following leaf traits were measured: specific leaf area (SLA; leaf area per unit of dry leaf mass), leaf dry matter content (LDMC; dry mass per unit of water-saturated fresh mass) and leaf thickness (LThick). Leaf density (LD) was calculated as the inverse of SLA divided by LThick (Witkowski \& Lamont 1991).

Stem morphological traits.- On the same six individuals per species and sampling site, we measured the following stem traits. Stem dry matter content (SDMC) was obtained as the ratio of dry to saturated fresh mass. Stem wood density (WD) was calculated as the dry mass divided by the stem fresh volume (based on the Archimedes principle, measuring the volume of water displaced by the immersion of the stem). 
Root morphological traits.- Roots were sampled at the individual level by excavating the first $20-30 \mathrm{~cm}$ of the soil depth near the plant basal stem, for four individuals per species and sampling site. We selected this specific soil depth based on a previous study with Mediterranean woody vegetation that demonstrated that the majority of fine roots appear in the first $27 \mathrm{~cm}$ of the soil depth (Silva \& Rego 2004). These root samples were used to measure four key below-ground traits in fine roots $(<2 \mathrm{~mm}$ in diameter): specific root area (SRA, root area per unit of root dry mass), root dry matter content (RDMC, root dry mass per unit of water-saturated fresh mass), root diameter (Rdi, average diameter of the fine roots) and root tissue density ( $\mathrm{RD}$, root dry mass per root volume). The root area, diameter and volume data were obtained by analysing the scanned root samples with WinRHIZO 2009 (Regent Instruments Inc., Quebec, Canada). The RD was calculated as the root dry mass divided by root volume.

Physiology-related traits.- Three functional traits related with plant physiology were considered: the leaf nitrogen concentration (LN), leaf chlorophyll (LChl, the concentration of chlorophyll per unit of fresh leaf mass) and leaf carbon isotopic ratio $\left(\delta^{13} \mathrm{C}\right) . \mathrm{Both} \mathrm{LN}$ and $\mathrm{LChl}$ are closely correlated with the mass-based maximum photosynthetic rate (Evans \& Poorter 2001; Pérez-Harguindeguy et al. 2013). The $\delta^{13} \mathrm{C}$ reflects a trade-off between the photosynthetic rate and stomatal conductance (Seibt et al. 2008) and provides a time-integrated measure of the intrinsic water-use efficiency (Farquhar et al. 1982). The LN and LChl were measured in leaves of six individuals per species and sampling site, whereas the $\delta^{13} \mathrm{C}$ was determined in a mixture of leaves from six different individuals per species and sampling site. 
Plant size trait.- Plant height (Phg) was measured as a functional trait commonly used to quantify plant size. Measurements were made on 10 individuals per species and sampling site, using a metric tape. In tall species, such as trees, plant height was estimated using the 'Christen height` meter, based on trigonometric principles (Klein 2007).

Seed trait.- Seed mass data were compiled from the published literature (García-Fayos 2001) and from seed databases ("Semillas Cantueso" at http://www.semillascantueso.com/es/, Jardín Botánico de Córdoba and IEED, Goethe-University Frankfurt at http://www.seeddispersal.info). Although it would have been preferable to obtain the seed data of the 38 species by direct collection, we rely on these data as representative of this functional trait for reproduction.

\section{Data analyses}

A general principal component analysis (PCA) was performed with the whole set of functional traits (15 traits) for the 38 woody plant species (average value for each species), to have an overview of the multidimensional spectrum of variation. Then, we performed a PCA for each organ (leaf, stem and root) separately (similarly to Freschet et al. 2010), using trait values at the species level.

The degree of coordination among traits belonging to different plant organs (leaf, stem and root) was determined through Standardized Major Axis (SMA) regressions, using the first PCA axis of each organ. The SMA is a statistical tool highly recommended for allometric studies (Warton et al. 2006) when there is no clear dependent or independent variable and there is an interest in knowing the slope between the two axes. 
The relationships between the morphological traits (in leaf, stem and root) and the physiology-related traits, plant size and seed mass were also explored by SMA fitting.

In order to control for the influence of species evolutionary history at the species level, all the above-described relationships were also determined by fitting a phylogenetic generalised least squares model. By calculating phylogenetically independent contrasts (PIC), we can assess the impact of phylogeny on our results (Webb et al. 2008; Verdú et al. 2013). For these PICs, we used the pgls function of the caper package (Orme 2011) for R (R Development Core Team 2011), which addresses phylogenetic non-independence among species by incorporating covariance between taxa into the calculation of the estimated coefficients. The phylogenetic relationships between species (see Appendix S3) were obtained with the help of the Phylomatic program, as implemented in Phylocom 4.2, and the reference phylogeny contained in R20120829.new (Webb et al. 2008). We resolved the topology of the tree (below the family level) with information from published phylogenies (Manos et al. 1999; Fernández-Mazuecos \& Vargas 2010; Verdú et al. 2013). Age estimates for nodes in the tree were taken from Verdú et al. (2013) and branch lengths were adjusted by using the BLADJ algorithm in Phylocom 4.2.

To assess if coordination of functional traits between organs (leaf, stem and root) is also consistent within environments located at different positions of the gradient, we first grouped species and sampling sites by using non-metric multidimensional scaling analysis (NMDS) with the function 'metaMDS' in Vegan. Then, for each of these groups of species representing major community types, we tested the relationships between organs using SMA regressions. 
For the analyses at the community level, the traits were weighted by the relative abundance of their constitutive species (using the species trait value for each plot), to calculate the community weighted means (CWMs) in each of the nine woody communities, according to Garnier et al. (2004). In order to obtain comparative results with respect to the species analysis, we also explored relationships between the morphological traits of different plant organs (leaf, stem and root) at the community level, and performed a PCA for each organ separately. The degree of coordination among traits belonging to different plant organs (leaf, stem and root) was determined through SMA regressions), using the first PCA axis of each organ.

All these analyses were conducted in the R 2.10·0 statistical platform (R Development Core Team 2011), using the packages "ape" (Paradis et al. 2004), “car” (Fox \& Weisberg 2011), “FactoMiner” (Lê et al. 2008), "phytools” (Revell 2012), “smatr” (Warton et al. 2012) and “vegan" (Dixon 2003).

\section{Results}

The results of the general PCA for the 15 functional traits and 38 woody species are shown in Fig. 1. The first PCA axis accounted for $44 \%$ of the overall variation and it was related in one extreme (negative values) with high values of traits (SLA, SRA, LChl and LN) that were positively correlated among themselves (Appendix S4) and representative of the resource-acquisition strategy. At the opposite extreme (positive values)

there were species with high values of traits (LDMC, LTh, SDMC, RDMC and $\delta^{13}$ ) that were also positively correlated among themselves 
(Appendix S4) and indicative of the resource-conservation strategy. The second principal component, which explained $15 \%$ of the overall variance, was represented mainly by variation in leaf density, seed mass and plant height. Similarly to the whole-plant PCA, the three organ PCAs showed high scores for their respective first principal components $(61 \%, 94 \%$ and $65 \%$ of overall variation explained for leaf, stem and root, respectively).

The SMA regressions among the set of morphological traits belonging to different organs (leaf, stem and root) (using the first PCA axis for each organ) provided significant and positive regression coefficients and their slopes did not significantly differ from 1 (Fig. 2, species analyses), indicating strong coordination and isometry among these organs.

In addition, the morphological traits (in leaf, stem and root) were significantly correlated with the physiology-related traits, such as leaf nitrogen (Fig. 3), $\delta^{13} \mathrm{C}$ and chlorophyll (with the exception of stem morphology and LChl; Appendix S5). Plant size was negatively related with root morphology and leaf morphology (Fig. 3). Regarding the links between vegetative and reproductive traits, we did not find any significant relationships between morphological traits and seed mass (Fig. 3). Only leaf morphology showed a positive correlation with seed mass, although this relationship was phylogenetically dependent (Appendix S6).

All the significant relationships observed at the species level were consistent after considering phylogenetically-independent contrasts (PIC; Appendix S6), except that commented above. 
Next, we analysed the consistency of the coordination of functional traits between organs under different environmental conditions. Firstly, three major groups of species representing the main community types were defined by NMDS (Appendix S7). The Wet group (scores of 0.6 to -0.2 on the first NMDS axis) was formed mainly by deciduous species from wetter sites; the Medium group (scores of -0.2 to 0.2 ) had species with intermediate characteristics; and the Dry group (scores of 0.2 to 0.6 ) had mainly sclerophyllous species from drier sites. Secondly, we performed SMA regression of functional traits separately for each of these three groups of species, and found weaker coordination at this level. Significant, positive SMA regressions were found only among the leaf and stem morphology for species from Wet and Medium sites, and their slopes did not differ significantly from 1 (Fig. 4).

At the community level, the trends obtained for the coordination among the morphological traits of leaf, stem and root were very similar to those found at the species level; interestingly, the correlation coefficients were higher than at the species level (Fig. 2). The most-striking difference was that the morphology of the leaf, root and stem was closely related with plant height and seed mass at the community level, despite not being correlated across species (Fig. 3).

\section{Discussion}

Evidence for a plant economics spectrum in Mediterranean environments 
Our results, based on 38 Mediterranean woody plant species, clearly show that morphological traits belonging to different plant organs are highly coordinated (Fig 2). In addition, the slopes of the SMA regressions between traits representative of leaf, stem and root morphology did not differ from one, indicating synchronisation of the structures of these organs. This suggests that these morphological traits have evolved in a correlated way as part of a whole-plant resource uptake strategy, and these relationships are not affected when phylogenetic relatedness is considered.

Understanding the strategic dimensions of trait variation along environmental gradients is a recent predominant goal of functional ecology (Freschet et al. 2010). In this respect, our results from a local Mediterranean gradient support some previous studies on woody and herbaceous plant species (Reich et al. 1998b; Freschet et al. 2010), but contrast with other results obtained for leaf and root traits along environmental gradients in tropical woody plants (Fortunel et al. 2012) and savannah-like grassland species (Tjoelker et al. 2005). These contradictory results suggest that the coordination between leaf, stem and root traits is not a universal trend, with large differences depending on the specific constraints of each ecosystem (Kembel \& Cahill 2011). For example, recent studies suggested that Amazonian trees optimise their survival and growth by investing differentially in leaves with respect to stem or root tissues (Baraloto et al. 2010; Fortunel et al. 2012), probably as a result of a trade-off between abiotic constraints and strong competition. We suggest that the coordination at the whole-plant level (leaf, stem and root) found in environments with more-adverse environmental conditions, such as sub-arctic (Freschet et al. 2010), arid (Liu et al. 2010) or semi-arid Mediterraneam ecosystems (this study), could be explained by the abiotic limitations of these sites, which may promote the convergence of functional traits in different organs. 
In addition, plant species with short-lived and low-density tissues (i.e. with higher values of SLA and SRA) showed higher LN and LChl values (i.e. potentially-higher growth rates). In contrast, species with long-lived tissues commonly associated with a more-conservative use of resources (i.e. high-density leaf, stem and root tissues) showed higher values of $\delta^{13} \mathrm{C}$ (typical of water-use-efficient species) (Reich 2014; de la Riva et al. 2014). The construction of plant tissues of woody Mediterranean species implies a trade-off between mechanical support, water conductance and storage of water and assimilates (Pratt 2007). These results support our initial hypothesis that the traits of leaves, stems and roots involved in the resource acquisition-conservation trade-off tend to co-vary, and demonstrate the existence of a whole-plant economics spectrum in Mediterranean forests and shrublands of southern Spain (see other examples in Freschet et al. 2010 and Méndez-Alonzo et al 2012).

However, the general trend of coordination between traits of different organs became weaker or disappeared at a lower spatial scale, when considering groups of species belonging to environmentally-similar sites (Fig. 4). Thus, we only found isometric relationships (slopes close to 1) between leaf and stem morphology in species from moist and intermediate conditions, but not for those typical from drier environments. Root traits were not significantly coordinated with leaf or stem traits within any of the three environments. The absence of a general and clear pattern of functional coordination when comparing results at different spatial scales could be due to the existence of different strategies operating at different levels. In this regard, Funk \& Cornwell (2013) suggested that trait variations among species within communities do not necessarily match the global pattern. At the global or landscape scale, abiotic factors may determine trait variation between communities in accordance with the economics spectrum (Wright et al. 2004) and also by variation of growth forms (i.e. deciduous/evergreen species; Wright et al. 2005). In our 
study, the whole set of species (including different growth forms) belonging to different communities were dispersed along the major acquisitiveconservative axis (see Fig. 4), resulting in a high functional coordination between organs. At the local scale, within a similar environment, the diversification of successful strategies is limited within the range of viable functional traits that allow plants to persist in this particular environment. Thus, if we focus at a smaller spatial scale (on a restricted fraction of the environmental gradient), functional coordination among organs is not so evident than at a higher spatial scale (Appendix S8). At a higher spatial scale, soil resource limitation (mainly water shortage) could be likely functioning as an initial abiotic filter excluding those species of the community with unfit trait values, whereas other factors could be promoting functional changes at a lower spatial scale.

Most studies have focused on trait coordination along natural wide environmental gradients (Wright et al. 2004; Tjoelker et al. 2005; Baraloto et al. 2010; Fortunel et al. 2012) or changing greenhouse (or laboratory) conditions (Reich et al. 1998b; Hernández et al. 2010). However, fewer studies have compared trait coordination within the same environmental conditions (but see Reich et al. 1997; Craine et al. 2005; Funk \& Cornwell 2013). Similarly, Craine et al. (2005) analysed trait coordination among organs (leaf and root) in different grass communities, finding coordination for only one of the six traits analysed (leaf and root nitrogen concentration), in accordance with the results of our study. Since the local scale of our study, only a relatively-small data set of species was analysed within each of the three environments; thus, more studies in Mediterranean and other biomes are needed to confirm the generality of such findings. 


\section{Variation in multidimensional functional traits}

Plant functional traits vary along three main dimensions: resource use, plant height and seed mass (Westoby 1998; Westoby \& Wright 2006; Reich 2014). Although we expected orthogonal relationships between plant height and the traits governing the plant resource economy, as found by Golodets et al. (2009) and Laughlin et al. (2010), our results refute that hypothesis. Instead, we found significant relationships between plant height and those leaf and root traits associated with higher resource acquisition. Hence, greater height implies a greater ability to compete for above-ground resources such as light (Bernard-Verdier et al. 2012), and this strategy could be advantageous for acquisitive species inhabiting more-productive and moister sites (Reich et al. 1992; Pérez-Ramos et al. 2012).

With regard to the reproductive functional dimension, our results indicate that regenerative (seed mass) and resource-use traits could be loaded on separate axes, as expected according to the LHS scheme (Westoby 1998). The reproductive dimension could be better explained by the reproductive effort strategy (Moles \& Westoby 2006), which entails a trade-off between seedling survival and the number of seeds produced per square metre of canopy, rather than by the acquisition-conservation axis that defines the plant economics spectrum. This finding supports previous studies in semi-arid forests (Laughlin et al. 2010) and Mediterranean grasslands (Liancourt et al. 2009), but contrasts with others that found a negative correlation between acquisitive traits (such as SLA or SRL) and seed mass in trees (Reich et al. 1998b) and grass species (Golodets et al. 2009). In our data set, seed mass was positively correlated with leaf density (a conservative trait), but this relationship depended on the phylogeny. Therefore, the orthogonality between vegetative and reproductive traits indicates that these functional traits may respond to 
different selective pressures of the environment (Liancourt et al. 2009) and the evolutionary context. However, due to the limitations of our study (we only considered one reproductive trait for a limited number of species), more studies are necessary to evaluate whether the relationships between vegetative and reproductive traits fulfil or not the above-mentioned predictions for a wider spatial scale.

\section{Relationships among functional traits at the community level}

At the community level, the links among traits belonging to different plant organs were consistently stronger than at the species level, in accordance with previous studies (Ackerly et al. 2002; Cingolani et al. 2007; Domínguez et al. 2012). According to our fourth hypothesis, dominant species will tend to have trait values that are better linked to their environments than those of less-abundant species, which could explain why the convergence of leaf, stem and root traits is stronger when using CWMs (Domínguez et al. 2012). To the best of our knowledge, our results also reveal - for the first time - the existence of a "plant community economics spectrum" (sensu Pérez-Ramos et al. 2012) along a local environmental gradient in Mediterranean forests.

One of the advantages of this community-level approach is its potential ability to highlight relevant ecosystem processes and functioning that cannot be predicted from the physiology or functional structure of individual plant species present in the community (Suding et al. 2008). For example, the morphological and physiological traits of leaves, stems and roots (particularly those related to the plant economics spectrum) determine ecosystem processes such as plant primary productivity or litter decomposability (Birouste et al. 2012; Choat et al. 2012; Freschet et 
al. 2013). It is necessary also to highlight the importance of incorporating the below-ground traits (especially of fine roots) into the functional analysis: first because fine roots represent approximately $48 \%$ of the annual litter inputs in forests (Freschet et al. 2013), and second because understanding the coordination between above- and below-ground traits may facilitate future predictions of root traits from leaf traits (which are easier to quantify) (Birouste et al. 2012).

With regard to the reproductive dimension, at the community level there was a strong coordination between morphological traits and seed mass, despite this not being shown at the species level (Fig. 3). Thus, in plant communities dominated by species with a conservative strategy, we would expect to find larger seeds whereas the opposite tendency would hold for communities dominated by species with acquisitive strategies. Consistent with these findings, Golodets et al. (2009) found that correlations between seed mass and morphological traits (SLA and LDMC) were stronger at the community than at the species level. These results support the tolerance-fecundity model (Muller-Landau 2010). According to this model, communities dominated by small-seeded species (usually with higher fecundity) will be favoured in more-productive sites, whereas large-seeded species will be more abundant in stressful habitats. Larger seeds produce larger seedlings, which are more robust and better able to escape size-dependent mortality (Pérez-Ramos et al. 2010); they form deeper and more-extensive roots, which can potentially capture more soil water during the dry season (Quero et al. 2007). This apparent covariation between morphological and reproductive traits found at the community level (but not across species) suggests that the combination of the economics spectrum with the tolerance-fecundity dimension could explain the most-successful strategies of the dominant woody plant species in Mediterranean environments. 


\section{Conclusions}

Our results show a high degree of functional coordination between traits belonging to different plant organs (leaf, stem and root). In addition, morphological traits were highly correlated with plant size as well as with key physiology-related traits. All these results suggest that the different plant organs may have a certain degree of convergence in resource use and resistance to physical hazards, supporting the hypothesis of integrated plant evolution (Kerkhoff et al. 2006; Freschet et al. 2010; Reich 2014). However, this general trend of coordination of functional traits between organs became weaker or disappeared when considering groups of species belonging to environmentally-similar sites. We also found that the relationships among functional traits were consistently stronger at the community level than across species, supporting the hypothesis that dominant species are better suited to the local environment and shape the functional patterns of vegetation. Interestingly, the strong covariation between vegetative (leaf, stem and root) and reproductive (seed) traits found at the community level suggests that in dominant species the economics spectrum and the tolerance-fecundity strategy could be coupled. Further studies in other floras and ecosystems worldwide are necessary to obtain solid conclusions on the functional coordination between plant organs on a larger, global scale.

\section{Acknowledgements}


We thank Miguel Verdú for phylogenetic tree and analyses and Jose Rafael Vera for plant traits analyses. We also thank Jardín Botánico de Córdoba (Francisca Herrera) and the Semillas Cantueso Company (José Angel Cantueso) for providing us seed mass data. We are very grateful to Francesco de Bello for his interesting comments on previous versions of the manuscript. This study was funded by the Spanish MEC coordinated project DIVERBOS (CGL2011-30285-C02-01 and C02-02), the Andalusian ANASINQUE project (PGC2010-RNM-5782), the Life

+ Biodehesa Project (11/BIO/ES/000726), ECO-MEDIT (CGL2014-53236-R) and European FEDER funds. The English was revised by Dr. David Walker.

\section{References}

Ackerly D.D., Knight C.A., Weiss S.B., Barton K, S.K. \& Starmer, K.P. 2002. Leaf size, specific leaf area and microhabitat distribution of chaparral woody plants: contrasting patterns in species level and community level analyses. Oecologia 130: 449-457.

Baraloto, C., Paine, C. E., Poorter, L., Beauchene, J., Bonal, D., (...) \& Chave, J. 2010. Decoupled leaf and stem economics in rain forest trees. Ecology Letters 13: 1338-47.

Bernard-Verdier, M., Navas, M., Vellend, M., Violle, C., Fayolle, A. \& Garnier, E. 2012. Community assembly along a soil depth gradient: contrasting patterns of plant trait convergence and divergence in a Mediterranean rangeland. Journal of Ecology 100: $1422-1433$. 
Birouste, M., Kazakou, E., Blanchard, A., \& Roumet, C. 2012. Plant traits and decomposition: are the relationships for roots comparable to those for leaves? Annals of Botany 109:463-72.

Castroviejo, S. 1986-2012. Flora Iberica, vols. 1-8, 10-15, 17-18, 21. Real Jardín Botánico, CSIC, Madrid.

Chave, J., Coomes, D., Jansen, S., Lewis, S.L., Swenson, N.G., \& Zanne, A.E. 2009. Towards a worldwide wood economics spectrum. Ecology Letters 12: 351-66.

Cingolani, A. M., Cabido, M., Gurvich, D. E., Renison, D., \& Díaz, S. 2007. Filtering processes in the assembly of plant communities: Are species presence and abundance driven by the same traits? Journal of Vegetation Science 18: 911-920.

Cornwell, W.K., Schwilk, D.W., \& Ackerly, D.D. 2006. A trait-based test for habitat filtering: convex hull volume. Ecology 87: $1465-1471$.

Craine, J. M., Lee, W. G., Bond, W. J., Williams, R. J., \& Johnson, L. C. 2005. Environmental constraints on a global relationship among leaf and root traits of grasses. Ecology 86: 12-19.

de la Riva, E. G., Pérez-Ramos, I., Fernández, C. N., Olmo, M., Arana, T. M., \& Villar, R. 2014. Rasgos funcionales en el género Quercus: estrategias adquisitivas frente a conservativas en el uso de recursos. Ecosistemas 23: 82-89.

de la Riva, E. G., Pérez-Ramos, I. M., Tosto, A., Navarro-Fernández, C. M., Olmo, M., Marañón, T., \& Villar, R. (2015). Disentangling the relative importance of species occurrence, abundance and intraspecific variability in community assembly: a trait-based approach at the whole plant level in Mediterranean forests. Oikos DOI:10.1111/oik.01875. 
Díaz, S., Hodgson, J.G., Thompson, K., Cabido, M., Cornelissen, J.H.C. et al. 2004. The plant traits that drive ecosystems: Evidence from three continents. Journal of Vegetation Science 15: 295-304.

Dixon, P. 2003. VEGAN, a package of R functions for community ecology. Journal of Vegetation Science 14: 927-930.

Domínguez, M.T., Aponte, C., Pérez-Ramos, I.M., García, L.V., Villar, R., \& Marañón, T. 2012. Relationships between leaf morphological traits, nutrient concentrations and isotopic signatures for Mediterranean woody plant species and communities. Plant and Soil 357: 407424.

Evans, J.R., \& Poorter, H. 2001. Photosynthetic acclimation of plants to growth irradiance: the relative importance of specific leaf area and nitrogen partitioning in maximizing carbon gain. Plant, Cell \& Environment 24(8): 755-767.

Farquhar, G. D., Learyb, M. H. O., \& Berry, J. A. 1982. On the relationship between Carbon isotope discrimination and the intercellular Carbon Dioxide concentration in leaves. Australian Journal of Plant Physiology 9: 121-137.

Fernández-Mazuecos, M. \& Vargas, P. 2010. Ecological rather than geographical isolation dominates Quaternary formation of Mediterranean Cistus species. Molecular Ecology 19: 1381-1395.

Fortunel, C., Fine, P.V., \& Baraloto, C. 2012. Leaf, stem and root tissue strategies across 758 Neotropical tree species. Functional Ecology 26: 1153-1161. 
Fox, J. \& Weisberg, S. 2011. Multivariate Linear Models in R. http://www.stat.ualberta.ca/ wiens/stat575/misc\%20resources/AppendixMultivariate-Linear-Models.pdf

Freschet, G.T., Cornelissen, J.H.C., van Logtestijn, R.S.P., \& Aerts, R. 2010. Evidence of the "plant economics spectrum" in a subarctic flora. Journal of Ecology 98: 362-373.

Freschet, G.T., Cornwell, W.K., Wardle, D.A., Elumeeva, T. G., Liu, W., Jackson, B. et al. 2013. Linking litter decomposition of above- and below-ground organs to plant-soil feedbacks worldwide. Journal of Ecology 101: 943-952.

Funk, J. L., \& Cornwell, W. K. (2013). Leaf traits within communities: context may affect the mapping of traits to function. Ecology 94: 18931897.

García-Fayos, P. 2001. Bases ecológicas para la recolección, almacenamiento y germinación de semillas de especies de uso forestal de la Comunidad Valenciana. Banc de Llavors Forestals (Generalitat Valenciana). Spain.

Garnier, E., Cortez, J., Billes, G., Navas, M.L., Roumet, C., Debussche,(...). \& Toussaint, J. P. 2004. Plant functional markers capture ecosystem properties. Ecology 85: 2630-2637.

Garnier, E., \& Navas, M. L. 2012. A trait-based approach to comparative functional plant ecology: concepts, methods and applications for agroecology. Agronomy for Sustainable Development 32: 365-399. 
Golodets, C., Sternberg, M., \& Kigel, J. 2009. A community level test of the leaf height seed ecology strategy scheme in relation to grazing conditions. Journal of Vegetation Science 20: 392-402.

Heberling, J. M., \& Fridley, J. D. 2012. Biogeographic constraints on the world-wide leaf economics spectrum. Global Ecology and Biogeography 21: 1137-1146.

Hernández, E. I., Vilagrosa, A., Pausas, J. G., \& Bellot, J. 2010. Morphological traits and water use strategies in seedlings of Mediterranean coexisting species. Plant Ecology 207: 233-244.

Kembel, S.W., \& Cahill, J.F. 2011. Independent evolution of leaf and root traits within and among temperate grassland plant communities. PloS One 6: e19992.

Kerkhoff, A.J., Fagan, W.F., Elser, J.J., \& Enquist, B.J. 2006. Phylogenetic and growth form variation in the scaling of nitrogen and phosphorus in the seed plants. The American Naturalist 168: 103-22.

Klein, C.H. 2007. Lecture Notes for the Teaching Module Forest Inventory. Institute of Forest Management, Faculty of Forest Sciences and Forest Ecology. Georg August Universität, Germany, 164 p.

Laughlin, D.C., Leppert, J.J., Moore, M. M., \& Sieg, C.H. 2010. A multi-trait test of the leaf-height-seed plant strategy scheme with 133 species from a pine forest flora. Functional Ecology 24: 493-501.

Laughlin, D. C. 2014. The intrinsic dimensionality of plant traits and its relevance to community assembly. Journal of Ecology 102: 186-193. 
Lavorel, S., Grigulis, K., McIntyre, S., Williams, N. S., Garden, D., (...) \& Bonis, A. 2008. Assessing functional diversity in the fieldmethodology matters! Functional Ecology 22: 134-147.

Lavorel, S. 2013. Plant functional effects on ecosystem services. Journal of Ecology 101: 4-8.

Lê, S., Josse, J., \& Husson, F. 2008. FactoMineR: an R package for multivariate analysis. Journal of Statistical Software 25: 1-18.

Liancourt, P., Tielbörger, K., Bangerter, S., \& Prasse, R. 2009. Components of 'competitive ability' in the LHS model: Implication on coexistence for twelve co-occurring Mediterranean grasses. Basic and Applied Ecology 10: 707-714.

Liu, G., Freschet, G.T., Pan, X., Cornelissen, J.H.C., Li, Y. \& Dong, M. 2010. Coordinated variation in leaf and root traits across multiple spatial scales in Chinese semi-arid and arid ecosystems. New Phytologist 188: 543-553

Manos, P.S., Doyle, J.J. \& Nixon, K.C. 1999. Phylogeny, biogeography, and processes of molecular differentiation in Quercus subgenus Quercus (Fagaceae). Molecular Phylogenetics and Evolution 12: 333-49.

Méndez-Alonzo, R., Paz, H., Zuluaga, R. C., Rosell, J. A., \& Olson, M. E. 2012. Coordinated evolution of leaf and stem economics in tropical dry forest trees. Ecology 93: 2397-2406.

Moles, A. T., \& Westoby, M. 2006. Seed size and plant strategy across the whole life cycle. Oikos 113: 91-105.

Muller-Landau, H. C. 2010. The tolerance-fecundity trade-off and the maintenance of diversity in seed size. Proceedings of the National Academy of Sciences 107: 4242-4247. 
Orme D. 2011 R-Forge: comparative analyses of phylogenetics and evolution in R. See http://cran.rproject.org/web/packages/caper/index.html

Paradis, E., Claude, J. \& Strimmer, K. 2004. APE: analyses of phylogenetics and evolution in R language. Bioinformatics 20: $289-290$.

Pérez-Harguindeguy, N., Díaz, S., Garnier, E., Lavorel, S., Poorter, H., (...) \& Cornelissen, J.H.C. 2013. New handbook for standardised measurement of plant functional traits worldwide. Australian Journal of Botany 61:167-234.

Pérez-Ramos, I. M. Gómez-Aparicio, L., Villar, R., Garcia, L. V. \& Marañón, T. 2010. Seedling growth and morphology of three oak species along field resource gradients and seed mass variation: a seedling-age dependent response. Journal of Vegetation Science 21: $419-437$.

Pérez-Ramos, I. M., Roumet, C., Cruz, P., Blanchard, A., Autran, P. \& Garnier, E. 2012. Evidence for a "plant community economics spectrum" driven by nutrient and water limitations in a Mediterranean rangeland of southern France. Journal of Ecology 100: 1315-1327.

Poorter, H. \& Garnier, E. 2007. Ecological significance of inherent variation in relative growth rate and its components. In: Functional Plant Ecology, 2nd edn (eds Punnaire FI, Valladares F), pp. 67- 100. CRC Press, Boca Raton, Florida.

Pratt, R. B., Jacobsen, A. L., Ewers, F. W., \& Davis, S. D. 2007. Relationships among xylem transport, biomechanics and storage in stems and roots of nine Rhamnaceae species of the California chaparral. New Phytologist 174: 787-798.

Prieto, I., Roumet, C., Cardinael, R., Dupraz, C., Jourdan, C., Kim, J. H. et al. 2015. Root functional parameters along a land-use gradient: evidence of a community-level economics spectrum. Journal of Ecology. doi: 10.1111/1365-2745.12351 
Quero, J. L., Villar, R., Marañón, T., Zamora, R., \& Poorter, L. 2007. Seed-mass effects in four Mediterranean Quercus species (Fagaceae) growing in contrasting light environments. American Journal of Botany 94: 1795-1803.

Reich PB, Walters MB, \& Ellsworth DS. 1992. Leaf life-span in relation to leaf, plant, and stand characteristics among diverse ecosystems. Ecological Monographs 62: 365-392.

Reich, P.B., Walters, M.B., Tjoelker, M.G., Vanderklein, D. \& Buschena, C. 1998a Photosynthesis and respiration rates depend on leaf and root morphology and nitrogen concentration in nine boreal tree species differing in relative growth rate. Functional Ecology 12: 395-405.

Reich, P. B., Tjoelker, M. G., Walters, M. B., Vanderklein, D. W., \& Buschena, C. 1998b. Close association of RGR, leaf and root morphology, seed mass and shade tolerance in seedlings of nine boreal tree species grown in high and low light. Functional Ecology 12: $327-338$.

Reich, P. B. 2014. The worldwide 'fast-slow' plant economics spectrum: a traits manifesto. Journal of Ecology 102: $275-301$.

Revell, L.J. 2012. Phytools: an R package for phylogenetic comparative biology (and other things). Methods in Ecology and Evolution 3: 217223.

Seibt, U., Rajabi, A., Griffiths, H. \& Berry, J.A. 2008. Carbon isotopes and water use efficiency: sense and sensitivity. Oecologia 155: 441-54.

Silva, J.S., \& Rego, F.C. 2004. Root to shoot relationships in Mediterranean woody plants from Central Portugal. Biologia 59: 1-7.

Suding, K. N., Lavorel, S., Chapin, F. S., Cornelissen, J.H.C., Díaz, S., (...) \& Navas, M.L. 2008. Scaling environmental change through the community-level: a trait-based response-and-effect framework for plants. Global Change Biology 14: 1125-1140. 
Tjoelker, M.G., Craine, J.M., Wedin, D., Reich, P.B., \& Tilman, D. 2005. Linking leaf and root trait syndromes among 39 grassland and savannah species. The New Phytologist 167: 493-508.

Verdú, M., \& Pausas, J. G. 2013. Syndrome driven diversification in a Mediterranean ecosystem. Evolution 67: 1756-1766.

Villar, R., Robleto, J. R., De Jong, Y., \& Poorter, H. 2006. Differences in construction costs and chemical composition between deciduous and evergreen woody species are small as compared to differences among families. Plant, Cell and Environment 29: 1629-1643.

Violle, C., Navas, M.L., Vile, D., Kazakou, E., Fortunel, C., Hummel, I. \& Garnier, E. 2007. Let the concept of trait be functional! Oikos 116: $882-892$.

Warton, D. I., Wright, I. J., Falster, D. S., \& Westoby, M. 2006. Bivariate line-fitting methods for allometry. Biological Reviews 81(2): 259-291.

Warton, D.I., Duursma, R.A., Falster, D.S., \& Taskinen, S. 2012. Smatr 3-an R package for estimation and inference about allometric lines. Methods in Ecology and Evolution 3: 257-259.

Webb, C.O., Ackerly, D.D. \& Kembel. S. W. 2008. Phylocom: software for the analysis of phylogenetic community structure and trait evolution. Bioinformatics 24: 2098-2100.

Westoby, M. 1998. A leaf-height-seed (LHS) plant ecology strategy scheme. Plant and Soil 199: 213-227.

Westoby, M. \& Wright, I. J. 2006. Land-plant ecology on the basis of functional traits. Trends in Ecology \& Evolution 21: 261-8.

Witkowski, E.T.F. \& Lamont, B.B. 1991. Leaf specific mass confounds leaf density and thickness. Oecologia 88: 486-493. 
Wright, I.J. \& Westoby, M. 2001. Understanding seedling growth relationships through specific leaf area and leaf nitrogen concentration: generalisations across growth forms and growth irradiance. Oecologia 127: 21-29.

Wright, I.J., Reich, P.B., Westoby, M., Ackerly, D.D., Baruch, Z., (...) \& Villar, R.. 2004. The worldwide leaf economics spectrum. Nature 428: 821-827.

Wright, I. J., Reich, P. B., Cornelissen, J. H., Falster, D. S., Groom, P. K., (...) \& Westoby, M. 2005. Modulation of leaf economic traits and trait relationships by climate. Global Ecology and Biogeography 14: 411-421.

\section{Supporting Information}

Appendix S1. Species list.

Appendix S2. Functional traits list.

Appendix S3. Phylogenetic tree.

Appendix S4. Pearson correlation coefficients between traits.

Appendix S5. Relationships between morphological traits with and the isotopic carbon fraction and leaf chlorophyll.

Appendix S6. Phylogenetic generalised least square analysis.

Appendix S7. Non-metric multidimensional scaling analysis.

Appendix S8. Illustrated figure of the scale effects. 


\section{Figure legends}

Figure 1. Principal Component Analysis (PCA) showing the plant economics spectrum, from conservative (right) to fast-growing or adquisitive (left) species. The variables (plant traits) used for the PCA are displayed with their vector. The plant economics spectrum is represented as a straight horizontal line (axis 1). See Appendix 1 and 2 for abbreviations of the traits and species names.

Figure 2. Standardized Major Axis (SMA) regressions between morphological traits belonging to different plant organs (leaf, stem and root), at the species (dark circles) and community (light-blue triangles) levels. For these analyses we used the first PCA axis of the different morphological traits belonging to different plant organs (leaf, stem and root). The Pearson correlation coefficient (r) is given and the level of significance is expressed as follows: *** $P<0.001$. The slopes of the regressions are indicated within brackets and they are not statistically different from $1(P>0.05)$.

Figure 3. Standardized Major Axis (SMA) regressions between morphological traits (leaf, black circles and solid lines; stem, grey circles and dotted lines; root, white circles and dashed lines) - ordered along an acquisitive-conservative gradient (given by the PCA first axis values) - and leaf nitrogen (LN), plant height (Phg) and seed mass (Smass), at the species (left column) and community (right column) levels. The Pearson correlation coefficient (r) is given and the SMA regression line is plotted when significant. The significance level is as follows: $*<0.05, * * P$ $<0.01, * * * P<0.001$; the sign ${ }^{+}$indicates that significant correlations were not consistent with phylogenetic contrast.

Figure 4. Standardized Major Axis (SMA) regression between morphological traits for species from three different environments: Wet (black circles and solid lines), Medium (grey circles and dashed lines) and Dry (white circles). The Pearson correlation coefficient (r) is given and the 
significance level is $* P<0.05$. The three groups of species were classified by a non-metric multidimensional scaling analysis (NMDS) (Appendix S7). 
Fig 1

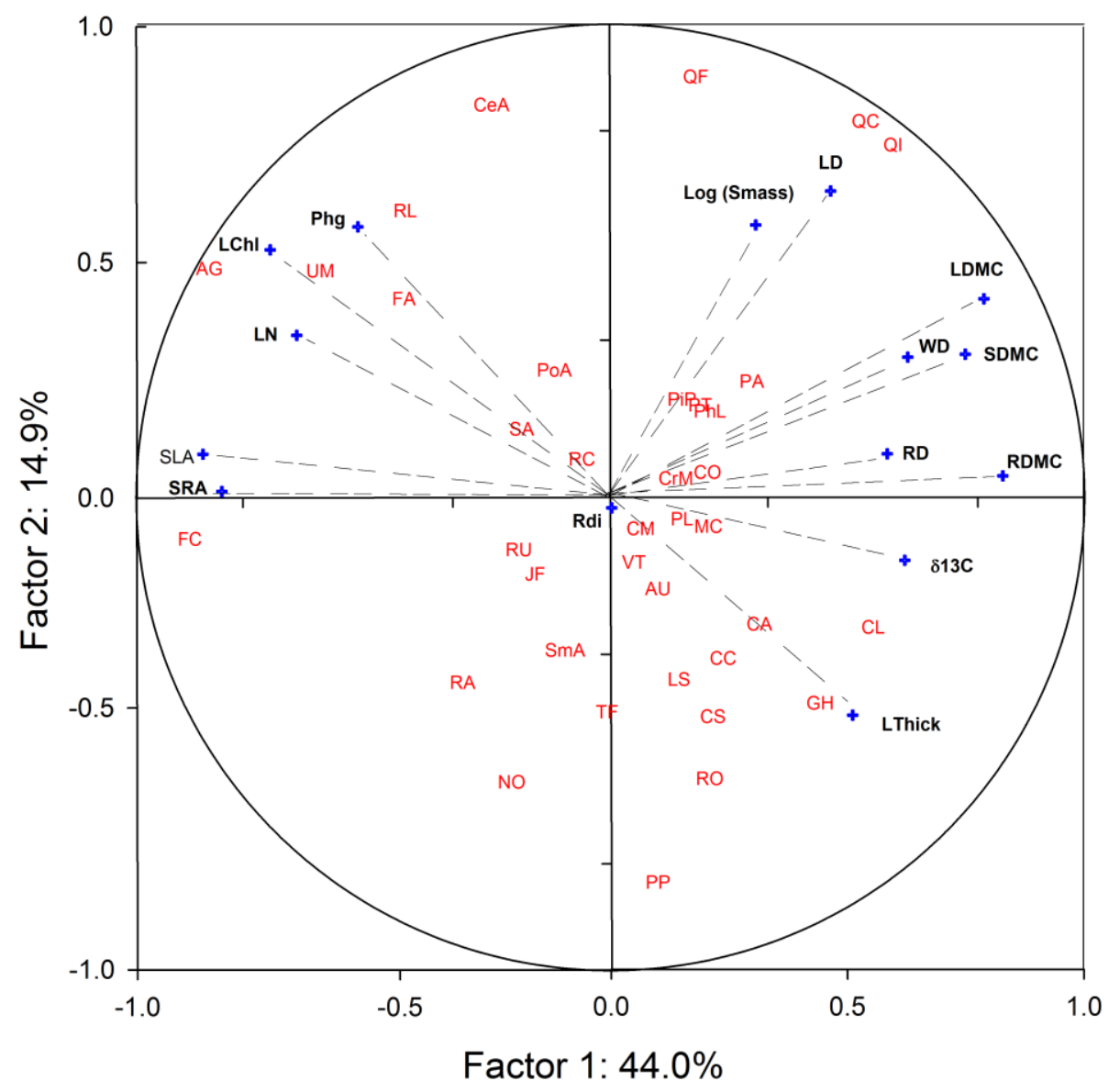


Fig. 2 
SPECIES

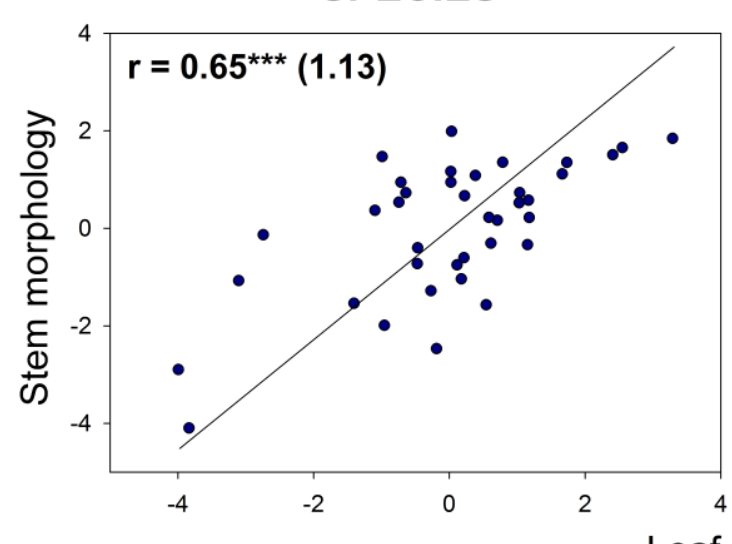

COMMUNITIES
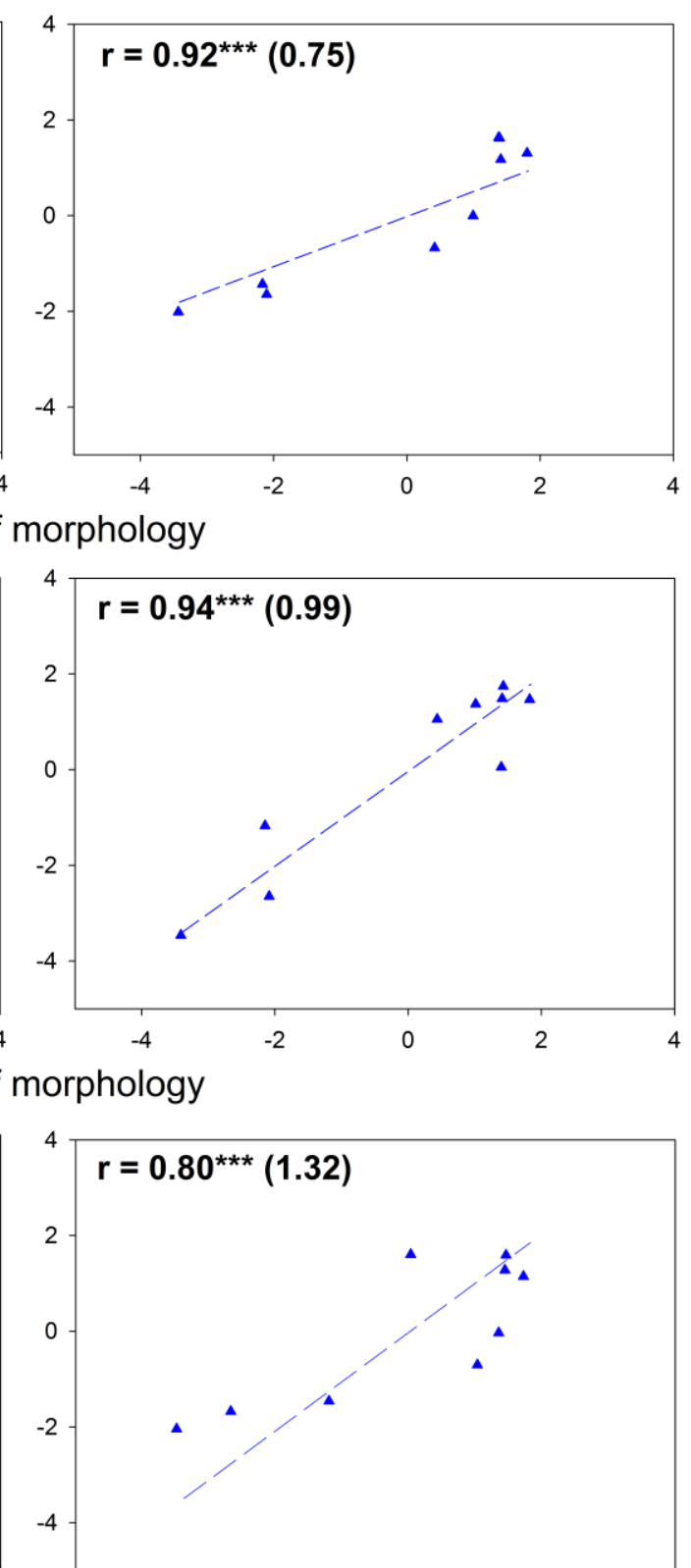
Fig 3 

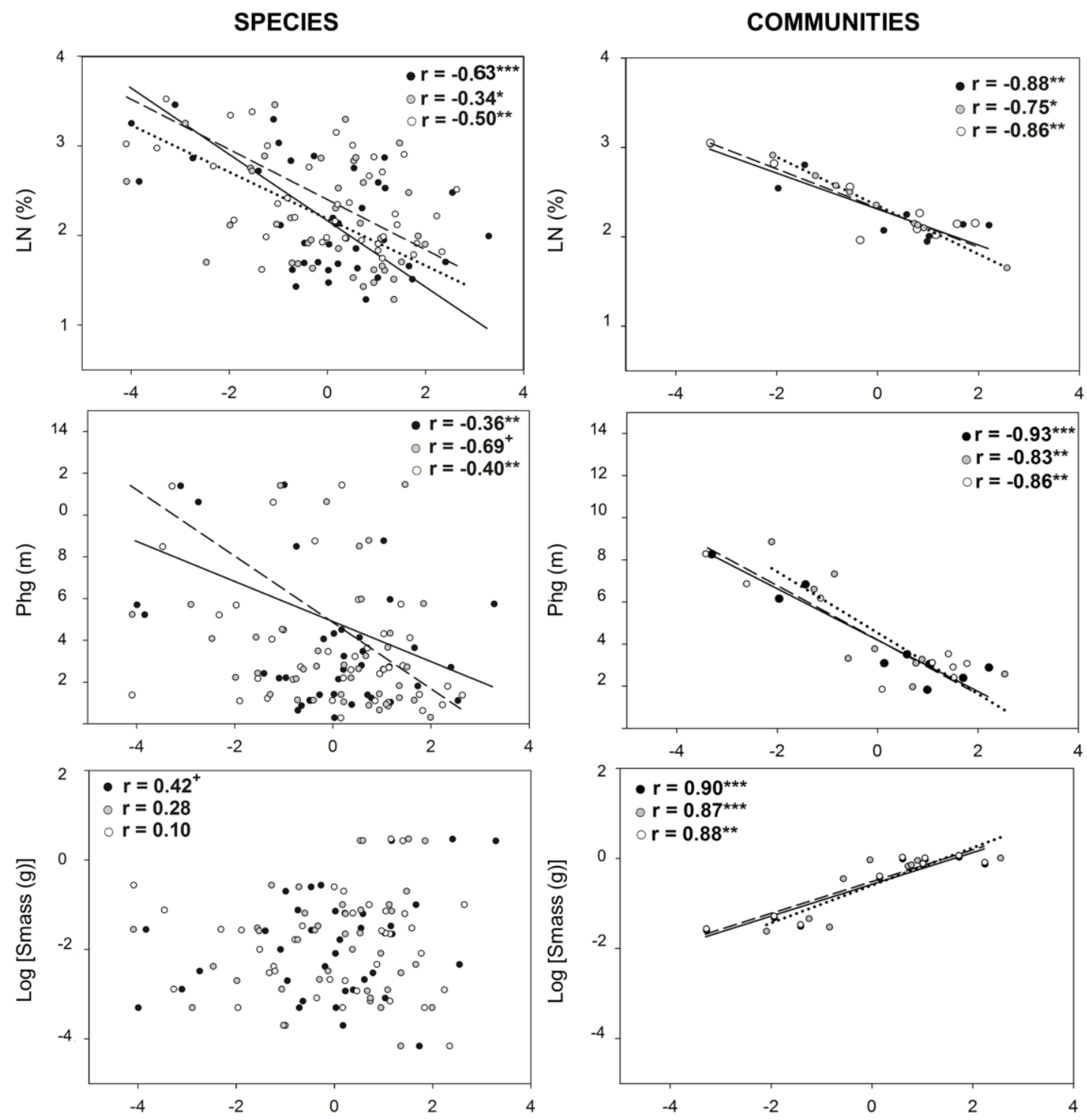

Acquisitive

Organ morphology (PCA 1 axis) 
Fig 4

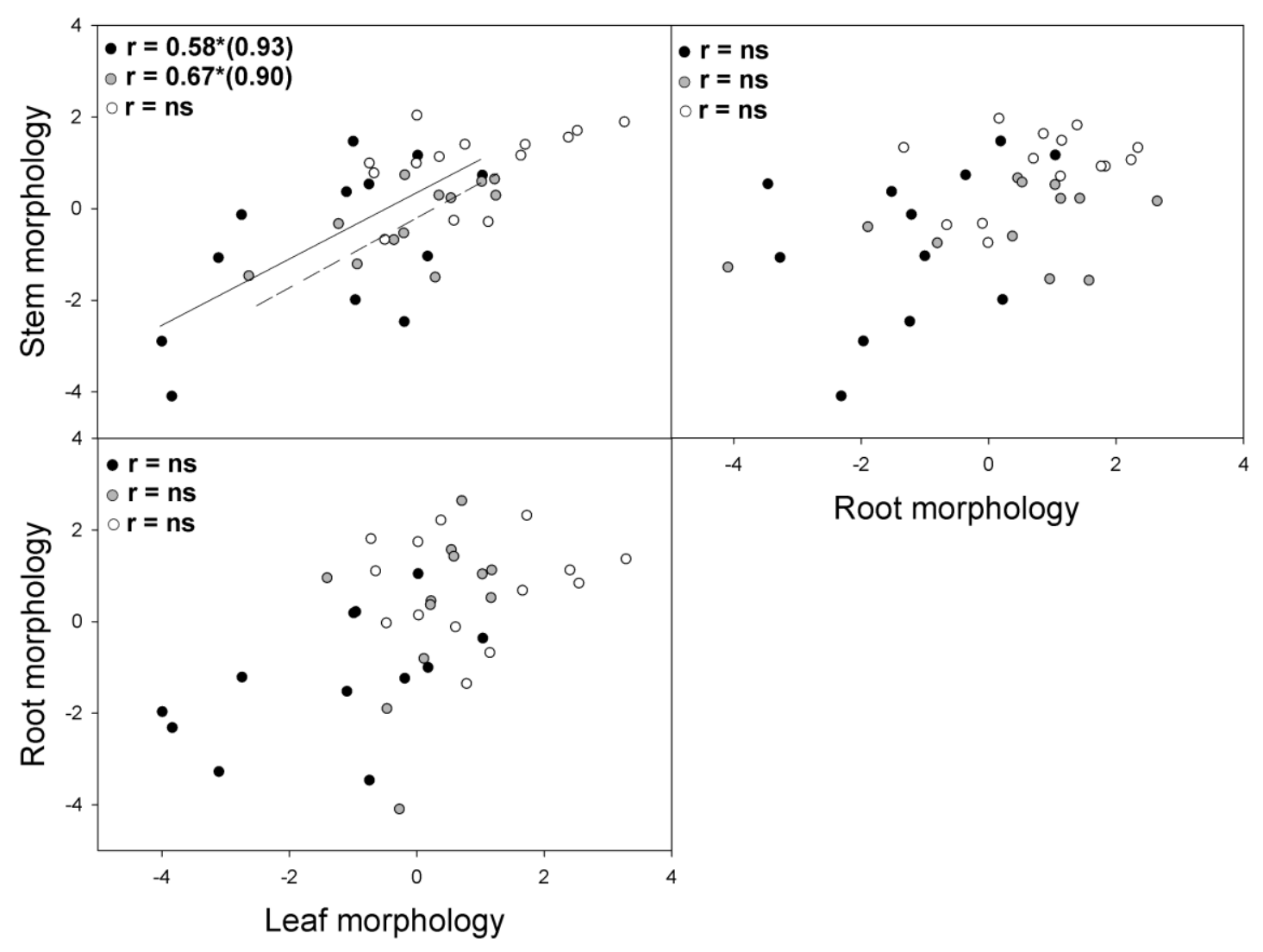


Appendix S1. Species studied, abbreviations and plant abundance (\%) in the different sampling sites.

\begin{tabular}{|c|c|c|c|c|c|c|c|c|c|c|c|c|c|}
\hline \multirow{2}{*}{ Species } & \multirow{2}{*}{ Abbreviation } & \multirow{2}{*}{ Family } & \multirow{2}{*}{ Life habit } & \multirow{2}{*}{ Leaf habit } & \multicolumn{3}{|c|}{ Virgen de Linares } & \multicolumn{3}{|c|}{ Popea } & \multicolumn{3}{|c|}{ Las Tonadas } \\
\hline & & & & & Upper & Medium & Lower & Upper & Medium & Lower & Upper & Medium & Lower \\
\hline Alnus glutinosa & AG & Betulaceae & Tree & Winter deciduous & 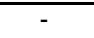 & & . & & - & 27.23 & & & 12.65 \\
\hline Arbutus unedo & $\mathrm{AU}$ & Ericaceae & Arborescent shrub & Evergreen & - & - & - & 5.25 & - & - & 19.63 & 3.62 & - \\
\hline Celtis australis & CeA & Cannabaceae & Tree & Winter deciduous & - & - & 18.34 & - & - & - & - & - & - \\
\hline Cistus albidus & CA & Cistaceae & Shrub & Evergreen & 19.16 & 2.58 & - & 2.83 & - & - & 4.88 & - & - \\
\hline Cistus crispus & CC & Cistaceae & Shrub & Evergreen & 7.35 & & - & & - & - & - & - & - \\
\hline Cistus ladanifer & $\mathrm{CL}$ & Cistaceae & Shrub & Evergreen & 4.29 & - & - & 10.49 & - & - & 10.80 & - & - \\
\hline Cistus monspeliensis & $\mathrm{CM}$ & Cistaceae & Shrub & Evergreen & - & - & - & - & - & - & - & 2.8 & - \\
\hline Cistus salvifolius & CS & Cistaceae & Shrub & Evergreen & - & 7.74 & - & & - & - & - & - & - \\
\hline Crataegus monogyna & $\mathrm{CrM}$ & Rosaceae & Arborescent shrub & Winter deciduous & - & - & 5.27 & - & - & - & - & - & - \\
\hline Cydonia oblonga & $\mathrm{CO}$ & Rosaceae & Tree & Winter deciduous & - & - & - & - & - & - & - & 2.25 & - \\
\hline Ficus carica & FC & Moraceae & Tree & Winter deciduous & - & - & - & - & - & 10.12 & - & - & - \\
\hline Fraxinus angustifolia & FA & Oleaceae & Tree & Winter deciduous & - & - & - & - & - & 30.60 & - & - & 37.96 \\
\hline Genista hirsuta & $\mathrm{GH}$ & Fabaceae & Shrub & Summer deciduous & 5.92 & 4.78 & - & 13.27 & - & - & 15.15 & - & - \\
\hline Jasminum fruticans & $\mathrm{JF}$ & Oleaceae & Shrub & Evergreen & - & & - & - & 7.02 & - & - & - & - \\
\hline Lavandula stoechas & LS & Lamiaceae & Shrub & Evergreen & 4.32 & 2.58 & - & - & - & - & - & - & - \\
\hline Myrtus communis & MC & Mirtaceae & Shrub & Evergreen & - & 6.89 & - & - & 2.72 & - & 4.48 & - & - \\
\hline Nerium oleander & NO & Apocynaceae & Arborescent shrub & Evergreen & - & & 11.706629 & - & 5.22 & 7.21 & - & - & - \\
\hline Phlomis purpurea & PP & Lamiaceae & Shrub & Evergreen & 5.56 & - & - & - & - & - & - & - & - \\
\hline Phillyrea angustifolia & PA & Oleaceae & Arborescent shrub & Evergreen & - & - & - & 4.62 & - & - & 9.10 & 4.36 & - \\
\hline Phillyrea latifolia & PhL & Oleaceae & Arborescent shrub & Evergreen & - & - & - & - & 45.05 & - & - & - & - \\
\hline Pistacia lentiscus & PiP & Anacardiaceae & Arborescent shrub & Evergreen & 10.02 & 33.61 & 17.63 & - & 2.99 & - & - & 5.65 & - \\
\hline Pistacia terebinthus & PL & Anacardiaceae & Arborescent shrub & Winter deciduous & - & - & - & - & 2.54 & - & - & - & - \\
\hline Populus alba & PT & Salicaceae & Tree & Winter deciduous & - & - & - & - & - & - & - & - & 6.68 \\
\hline Pyrus bourgaeana & PoA & Rosaceae & Tree & Winter deciduous & - & & - & - & - & - & - & 7.22 & - \\
\hline Quercus coccifera & $\mathrm{QC}$ & Fagaceae & Arborescent shrub & Evergreen & 19.71 & 7.74 & - & 23.50 & 7.37 & - & 9.29 & 7.96 & - \\
\hline Quercus faginea & QF & Fagaceae & Tree & Winter deciduous & 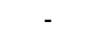 & & - & - & 2.65 & - & - & - & - \\
\hline Quercus ilex & QI & Fagaceae & Tree & Evergreen & 18.06 & 25.32 & - & - & - & - & 16.33 & 25.24 & - \\
\hline Rhamnus lycioides & $\mathrm{RL}$ & Rhamnaceae & Shrub & Evergreen & - & - & 5.64 & - & - & - & - & - & - \\
\hline Rosa canina & $\mathrm{RC}$ & Rosaceae & Shrub & Winter deciduous & - & - & - & - & - & - & - & 2.55 & - \\
\hline Rosmarinus officinalis & RO & Lamiaceae & Shrub & Evergreen & - & - & - & 31.06 & - & - & - & - & - \\
\hline Rubus ulmifolius & RU & Rosaceae & Shrub & Evergreen & - & - & 11.89 & - & - & 8.71 & - & 13.44 & 25.65 \\
\hline Ruscus aculeatus & RA & Asparagaceae & Shrub & Evergreen & - & - & - & - & 4.57 & - & - & 3.44 & - \\
\hline Salix atrocinerea & SA & Salicaceae & Tree & Winter deciduous & - & - & - & - & & - & - & - & 6.21 \\
\hline Smilax aspera & SmA & Smilacaceae & Vine & Evergreen & - & - & - & - & 2.61 & - & - & - & - \\
\hline Teucrium fruticans & $\mathrm{TF}$ & Lamiaceae & Shrub & Evergreen & - & - & - & 2.89 & - & - & - & - & - \\
\hline Ulmus minor & UM & Ulmaceae & Tree & Winter deciduous & - & - & 17.21 & - & - & 7.13 & - & - & - \\
\hline Viburnum tinus & VT & Adoxaceae & Arborescent shrub & Evergreen & - & - & - & - & 7.75 & - & - & 11.37 & - \\
\hline Vitis vinifera & vV & Vitaceae & Vine & Winter deciduous & - & - & 7.62 & - & - & - & - & - & - \\
\hline
\end{tabular}


1 Appendix S2. List of the 15 functional traits considered in this study, their 2 abbreviations, units and main role in plant functioning (based on the literature: Farquhar

3 et al. 1982; Bernard-Verdier et al. 2012; Garnier \& Navas 2012; Pérez-Harguindeguy et 4 al. 2013).

5

6

7

8

\begin{tabular}{|c|c|c|c|c|}
\hline Group & Trait & Abbreviation & Unit & Functional role \\
\hline Leaf morphology & $\begin{array}{l}\text { Specific leaf area } \\
\text { Leaf dry matter content } \\
\text { Leaf thickness } \\
\text { Leaf density }\end{array}$ & $\begin{array}{l}\text { SLA } \\
\text { LDMC } \\
\text { LThick } \\
\text { LD }\end{array}$ & $\begin{array}{l}\mathrm{m}^{2} \mathrm{~kg}^{-1} \\
\mathrm{mg} \mathrm{g}^{-1} \\
\mathrm{~mm}^{-} \\
\mathrm{g} \mathrm{cm}^{-3}\end{array}$ & $\begin{array}{l}\text { Light capture and growth rate } \\
\text { Physical resistance and stress tolerance } \\
\text { Gas exchange, water retention and physical resistance } \\
\text { Physical resistance, growth rate and stress tolerance }\end{array}$ \\
\hline Stem morphology & $\begin{array}{l}\text { Stem dry matter content } \\
\text { Stem wood density }\end{array}$ & $\begin{array}{l}\text { SDMC } \\
\text { SWD }\end{array}$ & $\begin{array}{l}\mathrm{mg} \mathrm{g}^{-1} \\
\mathrm{~g} \mathrm{~cm}^{-3}\end{array}$ & $\begin{array}{l}\text { Resistance to physical hazards } \\
\text { Physical resistance, growth rate and stress tolerance }\end{array}$ \\
\hline Root morphology & $\begin{array}{l}\text { Specific root area } \\
\text { Root dry matter content } \\
\text { Root diameter } \\
\text { Root density }\end{array}$ & $\begin{array}{l}\text { SRA } \\
\text { RDMC } \\
\text { Rdi } \\
\text { RD }\end{array}$ & $\begin{array}{l}\mathrm{m}^{2} \mathrm{~kg}^{-1} \\
\mathrm{mg} \mathrm{g}^{-1} \\
\mathrm{~mm}^{-} \\
\mathrm{g} \mathrm{cm}^{-3}\end{array}$ & $\begin{array}{l}\text { Water and nutrients acquisition } \\
\text { Resistance to physical hazards } \\
\text { Physical resistance, growth rate and stress tolerance } \\
\text { Physical resistance, growth rate and stress tolerance }\end{array}$ \\
\hline Leaf Physiology & $\begin{array}{l}\text { Leaf nitrogen concentration } \\
\text { Leaf chlorophyll } \\
\text { Isotopic carbon fraction }\end{array}$ & $\begin{array}{l}\mathrm{LN} \\
\mathrm{LChl} \\
\delta^{13} \mathrm{C}\end{array}$ & $\begin{array}{c}\% \\
\% g^{\%}\end{array}$ & $\begin{array}{l}\text { Light capture and photosynthetic rate } \\
\text { Light capture and photosynthetic rate } \\
\text { Gas exchange and water-use efficiency }\end{array}$ \\
\hline Plant Size & Plant height & Phg & $\mathrm{m}$ & Dispersal distance, light capture, above-ground competition \\
\hline Seed & Seed mass & Smass & $\mathrm{mg}$ & Dispersal capability and seedling survivorship \\
\hline
\end{tabular}


11 Appendix S3. The phylogenetic tree of the 38 studied species was obtained with the 12 help of the Phylomatic program, as implemented in Phylocom 4.2, and the reference 13 phylogeny contained in R20120829.new (Webb, Ackerly \& Kembel 2008).

38 Webb, C.O., Ackerly, D.D. \& Kembel, S.W. 2008. Phylocom: software for the analysis

39 of phylogenetic community structure and trait evolution. Bioinformatics 24: 2098-2100. 
40 Appendix S4. Pearson correlation coefficients for species data from the PCA analysis

41 (Fig.1). The significance level is as follows: $* P<0.05$, ** $P<0.01$, *** $P<0.001$.

42

\begin{tabular}{|c|c|c|c|c|c|c|c|c|c|c|c|c|c|c|}
\hline & LDMC & Lthick & LD & SDMC & WD & SRA & RDMC & Rdi & $\mathrm{RD}$ & LN & LChl & $\delta \mathrm{C}^{13}$ & Phg & Seed mass \\
\hline SLA & $-0.74^{\star \star \star}$ & $-0.61^{\star * *}$ & $-0.47^{\star \star}$ & $-0.55^{\star * *}$ & $-0.57^{* * *}$ & $0.67^{* \star *}$ & $-0.58^{\star \star \star}$ & -0.20 & $-0.32^{*}$ & $0.62^{* \star *}$ & $0.66^{\star \star \star}$ & $-0.66^{\star * *}$ & $0.52^{\star \star}$ & -0.16 \\
\hline Lthick & & & -0.22 & $0.36^{*}$ & $0.32^{*}$ & -0.31 & 0.28 & 0.03 & 0.15 & $-0.33^{*}$ & $-0.59^{* * *}$ & $0.51^{* *}$ & $-0.43^{* *}$ & -0.20 \\
\hline SDMC & & & & & $0.90^{\star \star *}$ & $-0.34^{*}$ & $0.48^{* *}$ & -0.21 & $0.39^{*}$ & -0.29 & -0.25 & 0.31 & -0.16 & 0.14 \\
\hline WD & & & & & & $-0.51^{\star *}$ & $0.66^{\star * \star}$ & -0.13 & $0.48^{\star \star}$ & $-0.38^{*}$ & $-0.40^{* *}$ & 0.39 & -0.23 & 0.15 \\
\hline SRA & & & & & & & $-0.87^{\star * *}$ & -0.19 & $-0.67^{* * *}$ & $0.50^{*}$ & $0.63^{\star \star *}$ & -0.49 & $0.48^{* *}$ & -0.22 \\
\hline RD & & & & & & & & & & $-0.41^{\star \star *}$ & -0.31 & 0.19 & -0.26 & -0.09 \\
\hline LN & & & & & & & & & & & $0.70^{\star \star \star}$ & $-0.40^{* *}$ & $0.58^{\star \star *}$ & 0.09 \\
\hline LChl & & & & & & & & & & & & $-0.55^{\star * \star}$ & $0.68^{\star * *}$ & -0.07 \\
\hline $\mathrm{z}^{13}$ & & & & & & & & & & & & & -0.29 & 0.19 \\
\hline Phg & & & & & & & & & & & & & & 0.11 \\
\hline
\end{tabular}

43

44 
45 Appendix S5.- Relationships between morphological traits (leaf, black circles and solid 46 lines; stem, grey circles and dotted lines; root, white circles and dashed lines) - ordered 47 along an acquisitive-conservative gradient (given by the PCA first axis values) - and the 48 isotopic carbon fraction $\left(\delta^{13} \mathrm{C}\right)$ and leaf chlorophyll (LChl), at the species (left column) 49 and community (right column) levels. The Pearson correlation coefficient (r) is given 50 and the standard major axis (SMA) regression line is plotted when significant. The 51 significance level is as follows: $* P<0.05$, ** $P<0.01$, *** $P<0.001$.

\section{SPECIES}
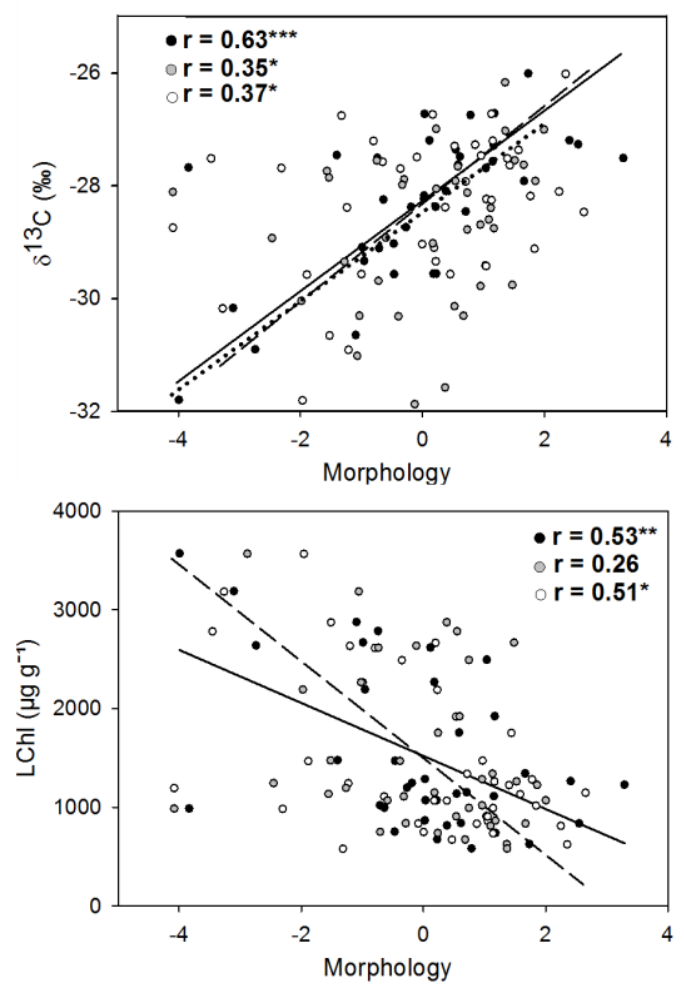

Acquisitive

\section{COMMUNITIES}
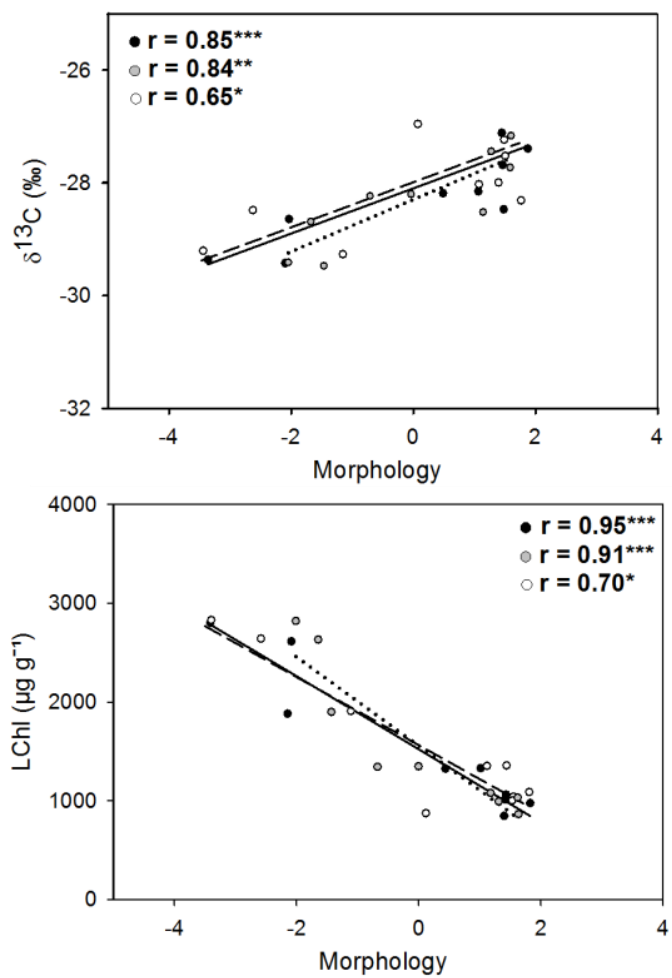

Conservative 
55 Appendix S6.- Results for the phylogenetic generalised least square (PGLS). The 56 significant results $(P<0.05)$ show the phylogenetic independence for these 57 relationships.

58

59

60

61

\begin{tabular}{|c|c|c|c|c|c|c|}
\hline & \multicolumn{2}{|c|}{ LEAF MORPHOLOGY } & \multicolumn{2}{|c|}{ STEM MORPHOLOGY } & \multicolumn{2}{|c|}{ ROOT MORPHOLOGY } \\
\hline & $\mathrm{P}$ & $\mathrm{R}^{2}$ & $\mathrm{P}$ & $\mathrm{R}^{2}$ & $\mathrm{P}$ & $\mathrm{R}^{2}$ \\
\hline LN & 0.01 & 0.15 & 0.05 & 0.07 & 0.00 & 0.23 \\
\hline LChl & $<0.001$ & 0.25 & ns & & $<0.001$ & 0.28 \\
\hline$\delta^{13} \mathrm{C}$ & $<0.001$ & 0.33 & 0.00 & 0.22 & 0.02 & 0.11 \\
\hline Phg & 0.06 & 0.06 & ns & & 0.01 & 0.14 \\
\hline Log(Smass) & ns & & ns & & ns & \\
\hline LEAF MORPHOLOGY & - & - & $<0.001$ & 0.38 & $<0.001$ & 0.28 \\
\hline STEM MORPHOLOGY & - & - & - & - & 0.00 & 0.21 \\
\hline
\end{tabular}

62 
63 Appendix S7.- Non-metric multidimensional scaling (NDMS) ordination of species 64 composition along the nine plant communities analysed, separating three groups: Wet 65 (black circles), Medium (grey) and Dry (white) (see also de la Riva et al. 2015).

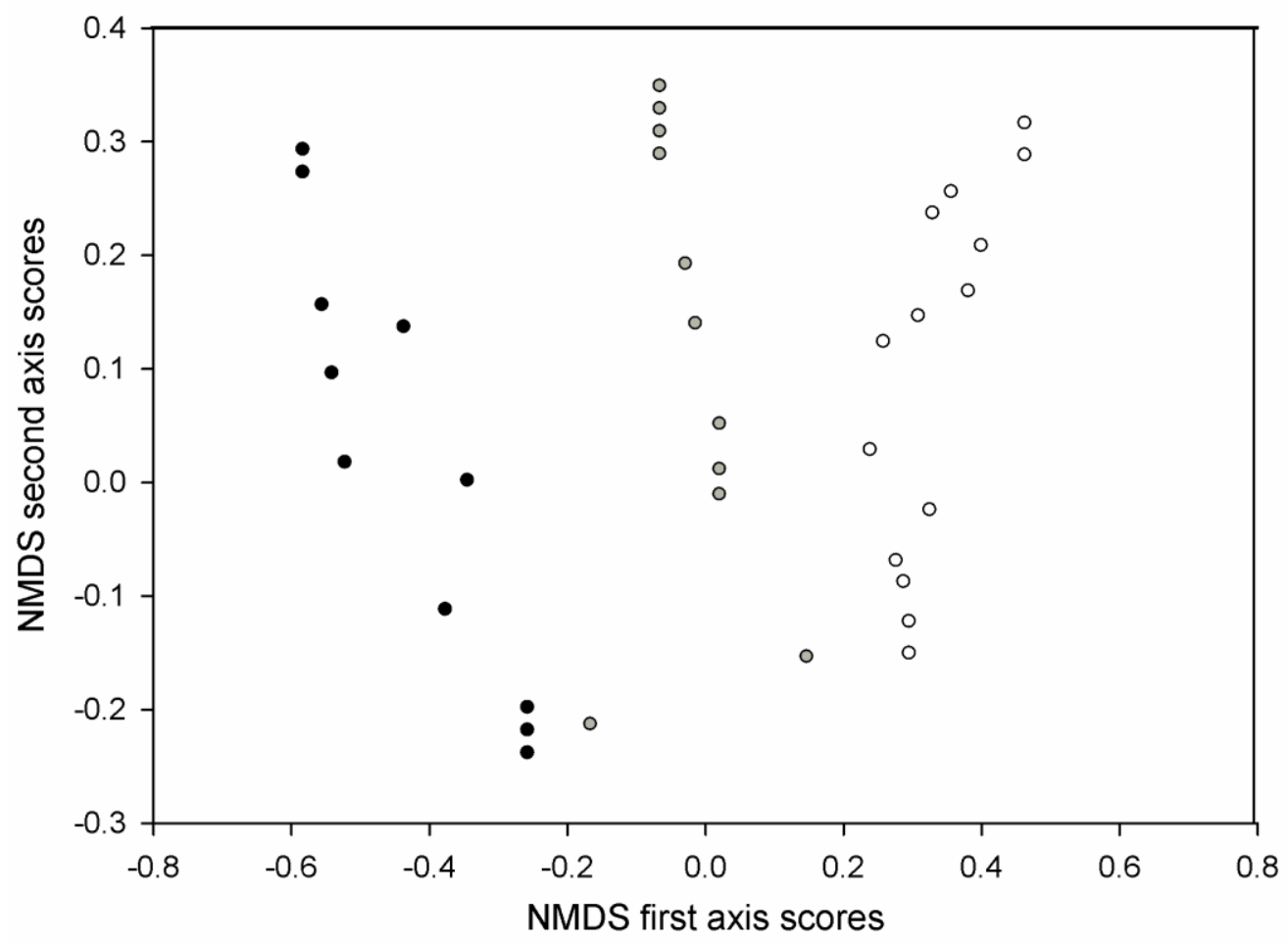

66

67 
68 Appendix S8. Standardized Major Axis analysis illustrating the scale effects.

69 Functional coordination between root and leaf morphology was compared at the

70 landscape (i.e including the whole environmental gradient) and at a lower spatial scale 71 (i.e. at three different points of the gradient). The high level of coordination found at the 72 landscape level dissapeared at a lower spatial scale (particularly in dry environments; 73 right panel). See Figures 2 and 4 for more details.

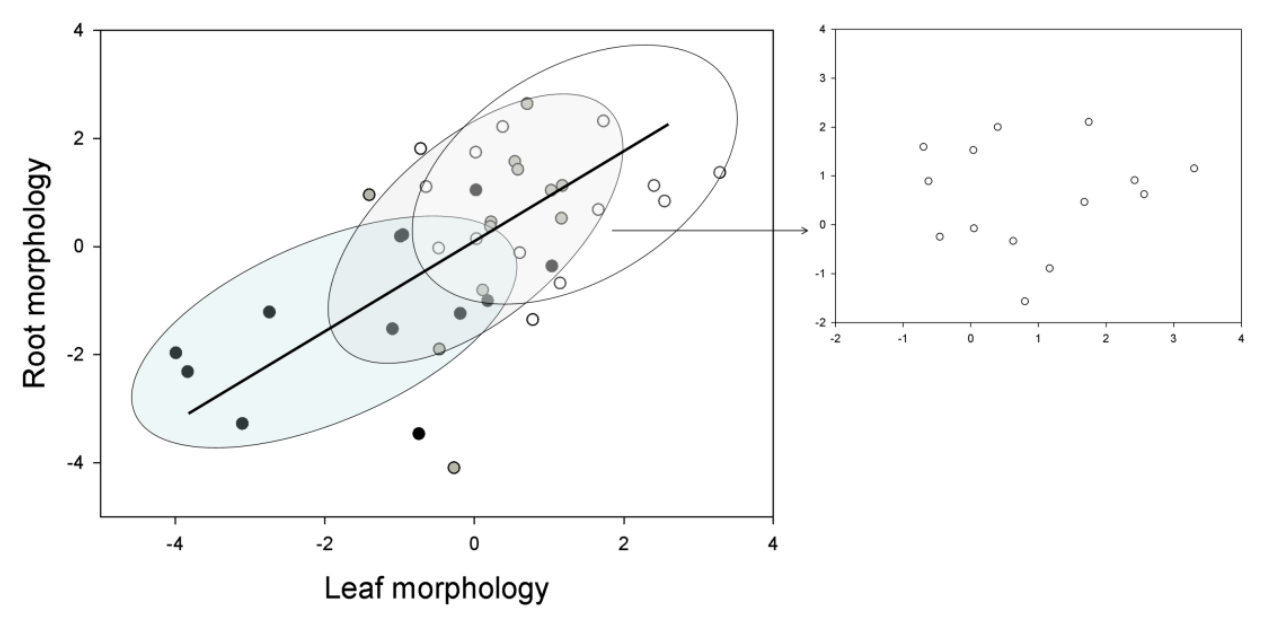

74 